Genoveva von Brabant 
Ars et Scientia

Schriften zur Kunstwissenschaft

Band 18

Herausgegeben von

Bénédicte Savoy,

Michael Thimann und

Gregor Wedekind 


\section{Ulf Dingerdissen}

\section{Genoveva von Brabant}

Ein romantisches Schlüsselthema in der bildenden Kunst des 19. Jahrhunderts 
ISBN 978-3-11-052110-8

eISBN (PDF) 978-3-11-052292-1

eISBN (EPUB) 978-3-11-0522181

ISSN 2199-4161

\section{Library of Congress Control Number: 2018936158}

\section{Bibliografische Information der Deutschen Nationalbibliothek}

Die Deutsche Nationalbibliothek verzeichnet diese Publikation in der Deutschen Nationalbibliografie; detaillierte bibliografische Daten sind im Internet über http://dnb.dnb.de abrufbar.

(C) 2018 Walter de Gruyter GmbH, Berlin/Boston

Satz: SatzBild, Sabine Taube, Kieve

Coverabbildung: Moritz von Schwind, Die Engel erscheinen Genoveva, Kunst Museum Winterthur, Depositum der Stiftung Oskar Reinhart, Inv.-Nr.: 364

Druck und Bindung: Beltz Bad Langensalza GmbH, Bad Langensalza

www.degruyter.com 